\title{
The use of neural networks for the prediction of cone penetration resistance of silty sands
}

\author{
Yusuf Erzin $^{1} \cdot$ Nurhan Ecemis ${ }^{2}$
}

Received: 10 March 2015/Accepted: 21 May 2016/Published online: 7 June 2016

(C) The Natural Computing Applications Forum 2016

\begin{abstract}
In this study, an artificial neural network (ANN) model was developed to predict the cone penetration resistance of silty sands. To achieve this, the data sets reported by Ecemis and Karaman, including the results of three high-quality field tests, namely piezocone penetration test, pore pressure dissipation tests, and direct push permeability tests performed at 20 different locations on the northern coast of the Izmir Gulf in Turkey, have been used in the development of the ANN model. The ANN model consisted of three input parameters (relative density, fines content, and horizontal coefficient of consolidation) and a single output parameter (normalized cone penetration resistance). The results obtained from the ANN model were compared with those obtained from the field tests. It is found that the ANN model is efficient in determining the cone penetration resistance of silty sands and yields cone penetration resistance values that are very close to those obtained from the field tests. Additionally, several performance indices such as the determination coefficient, variance account for, mean absolute error, root mean square error, and scaled percent error were computed to examine the performance of the ANN model developed. The performance level attained in the ANN model shows that the ANN model developed in this study can be employed for predicting cone penetration of silty sands quite efficiently.
\end{abstract}

Yusuf Erzin

yusuf.erzin@cbu.edu.tr

1 Department of Civil Engineering, Faculty of Engineering, Celal Bayar University, 45140 Manisa, Turkey

2 Department of Civil Engineering, Faculty of Engineering, Izmir Institute of Technology, 35430 Izmir, Turkey
Keywords Artificial neural networks - Cone penetration resistance $\cdot$ Horizontal coefficient of consolidation - Silty sand

\section{Introduction}

Several in situ tests, namely the standard penetration test (SPT), cone penetration test (CPT), flat dilatometer test (DMT), pressuremeter test (PMT), and vane shear test (VST), have been commonly used to obtain the engineering parameters of the soils in the subsurface needed for geotechnical design [1]. Currently, among these methods, the cone penetration test (CPT) is considered one of the most useful in situ tests and is widely used in onshore and offshore soil investigations [1]. The advantages of CPT tests are: (1) fast and continuous profiling, (2) repeatable and reliable data (not operator-dependent), (3) economical and productive, and (4) strong theoretical basis for interpretation [2]. The disadvantages of CPT tests are: (1) relatively high capital investment, (2) requiring skilled operators, (3) no soil sample, during a CPT, and (4) penetration that can be restricted in gravel/cemented layers [2]. The CPT measures the cone penetration resistance and the sleeve friction resistance. The piezocone penetration test (CPTu) measures additional parameter that is the pore water pressure. These measurements can be effectively used for the following applications: (1) to classify soil identification, (2) to directly estimate pile capacity from the $\mathrm{CPTu},(3)$ to evaluate soil properties through an appropriate correlation, especially the undrained shear strength, (4) to determine bearing capacity and settlement of the shallow foundations, (5) to control compaction in ground improvement, (6) to design wick or sand drains, and (7) to evaluate the soil liquefaction [2]. Therefore, the CPTu can 
be used for a wide range of geotechnical engineering applications [1].

Artificial neural networks (ANNs) have been successfully applied to many applications in civil engineering due to their heuristic problem-solving capabilities [3]. An ANN is one of the AI approaches that can be categorized as "machine learning" [3]. It has the ability to be similar to biological neurons [4]. This brain-like structure makes ANN models superior to most traditional methods in making predictions that has possessed high degrees of nonlinearity or a complex input pattern with a complex output pattern [3]. Evolving from neurobiological insights, ANN, similar to the brain, has an astonishing capacity to learn from example input-output training data sets [3]. Recently, ANNs have been found to be a useful tool to solve many problems in the field of the geotechnical engineering [3]. Since the early 1990s, ANNs have been effectively applied to almost every problem in geotechnical engineering, including constitutive modeling [5, 6]; geomaterial properties [3, 7-9]; bearing capacity of pile [10, 11]; slope stability [12-16]; shallow foundations [17-19]; liquefaction potential [20-26]; and tunnels and underground openings $[27,28]$.

In this study, ANNs, with respect to the above advantages, were utilized to predict the normalized cone penetration resistance $\left(q_{c l N}\right)$ of silty sands. To achieve this, the results of three high-quality field tests [29], namely piezocone penetration tests $(\mathrm{CPTu})$, pore pressure dissipation tests (PPDT), and direct push permeability tests (DPPT) performed at 20 different locations on the northern coast of the Izmir Gulf in Turkey, were used in the development of the ANN model. The ANN model consisted of three input parameters (relative density, fines content, and horizontal coefficient of consolidation) and a single output parameter $\left(q_{c 1 N}\right)$. The results obtained from the ANN model were compared with those obtained from the field tests and found very close to them. Moreover, the determination coefficient $\left(R^{2}\right)$, the values of variance account for (VAF), the mean absolute error (MAE), root mean square error (RMSE), and scaled percent error (SPE) indices were calculated to check the prediction performance of the ANN model developed. The ANN model has shown high prediction performance according to the performance indices computed.

\section{Artificial neural networks}

Artificial neural networks (ANNs) are numerical modeling techniques inspired by the functioning of the human brain [30]. The current interest in ANNs is largely due to their ability to mimic natural intelligence in its learning from experience $[4,31]$. The structure and operation of ANNs can be found in many applications (e.g., Fausett [4]; Zurada [31]; Hecht-Nielsen [32]; Maren et al. [33]; Ripley [34]). The typical structure of the ANN consists of a number of processing elements (PEs) commonly called as neurons that are fully or partially linked via connection weights [30]. These PEs are usually formed in layers: an input layer, one or more hidden layers, and an output layer. In the input layer, data are presented to the network. The output layer holds the response of the network to the input. The hidden layers enable these networks to represent and compute complicated associations between inputs and outputs. This ANN architecture is commonly called as a fully interconnected feed-forward multilayer perceptron (MLP). Additionally, there is also a bias, which is only connected to the neurons in the hidden and output layers, with modifiable weighted corrections.

The number of hidden layers used depends on the nature of the problem and so the degree of the complexity of the problem. ANNs with one or two hidden layers and adequate number of hidden neurons are found to be quite useful for most problems (i.e., Goh [35]; Orbanić and Fajdiga [36]; Sonmez et al. [37]). There are various methods (i.e., Hecht-Nielsen [32]; Hush [38]; Kaastra and Boyd [39]; Kanellopoulas and Wilkinson [40]; Grima and Babuska [41]; Haque and Sudhakar [42]) for the determination of the number of neurons in the hidden layer. Nevertheless, these methods present only general guidelines for the selection of a sufficient number of neurons.

The neural network "learns" by adjusting the weights of the neurons in response to the errors between the actual and the target output values. Several learning algorithms have been developed. The back-propagation learning algorithm, the most commonly used neural network algorithm [9, 35, 43-48], has been successfully applied with to model many phenomena in the field of geotechnical engineering [49-51]. In this algorithm, learning is performed through the gradient descent on the sum of the squares of the errors for all the training patterns $[43,49]$. Each neuron in a layer receives and processes weighted inputs from neurons in the previous layer and transmits its output to neurons in the following layer through links. Each link is assigned a weight which is a numerical estimate of the connection strength. The weighted summation of inputs to a neuron is converted to an output according to a nonlinear transfer function. The common transfer function widely used in the literature is the sigmoid function. The changes in the weights are proportional to the negative of the derivative of the error term. One pass through the set of training patterns, together with the associated updating of the weights, is called a cycle or an epoch. Training is performed by repeatedly presenting the entire set of training patterns (updating the weights at the end of the each epoch) until the average sum-squared error over all the training patterns 
is minimal and within the tolerance specified for the problem.

At the end of the training phase, the neural network should correctly reproduce the target output values for the training data; provided errors are minimal (i.e., convergence occurs). The associated trained weights of the neurons are then stored in the neural network memory. In the next phase, the trained neural network is fed a separate set of data. In this validation phase, the neural network predictions using the trained weights are compared to the target output values. The performance of the overall ANN model can be evaluated by several criteria [27, 52, 53]. These criteria include coefficient of determination $R^{2}$, mean squared error, mean absolute error, minimal absolute error, and maximum absolute error. A well-trained model should result in an $R^{2}$ close to 1 and small values of error terms.

In this work, the determination of cone penetration resistance has been modeled using the ANN in which network training was accomplished with the neural network toolbox written in MATLAB environment (Math Works 7.0 Inc. 2006) and the Levenberg-Marquardt backpropagation learning algorithm [54] was utilized in the training stage. The field investigations, which have yielded the data for the ANN model, are presented in the following section.

\section{Field testing program}

In this study, the data sets reported by Ecemis and Karaman [29], including the results of three high-quality field tests performed at 20 different locations on the northern coast of the Izmir Gulf, were used in the development of the ANN model. In their study area, the soil consisted of mainly quaternary sediments. These sediments are mostly saturated and are formed by sedimentation of the alluvial deposits transported by the Gediz River. Figure 1 displays a view of test locations. At each of these given locations, piezocone penetration test $(\mathrm{CPTu})$, standard penetration test (SPT), pore pressure dissipation test (PPDT), and direct push permeability test (DPPT) were conducted [29]. In the ANN model, the results of CPTu, PPDT, and DPPT were used while developing the ANN model. The details of these tests can be found at Ecemis and Karaman [29].

The cone penetration resistance qc, friction resistance fs, and pore water pressures above the cone face (referred to as the $\mathrm{u}_{2}$ position) for each $1 \mathrm{~cm}$ of penetration were obtained from the piezocone penetration tests. The probe used in the tests had $60^{\circ}$ tip angle and $35.7 \mathrm{~mm}$ diameter. The measured cone penetration resistance and friction resistance values were normalized based on the equations stated below [55]: $q_{c 1 N}=C_{q}\left(\frac{q_{\mathrm{c}}}{P_{\mathrm{a}}}\right)$

$F=\frac{f_{\mathrm{s}}}{q_{\mathrm{c}}-\sigma_{\mathrm{v}}}$

$C_{q}=\left(\frac{P_{\mathrm{a}}}{\sigma_{\mathrm{vo}}^{\prime}}\right)^{n}$

where $P_{\mathrm{a}}=$ atmospheric pressure in the same units used for $q_{\mathrm{c}} ; \sigma_{\mathrm{vo}}^{\prime}=$ effective vertical stress in the same units as $P_{\mathrm{a}} ; F=$ normalized friction resistance in percent; and $n=0.784-0.521 D_{\mathrm{r}}[56]$, which is the stress exponent.

The cone penetration resistance is significantly affected by relative density [57]. This is because $q_{\mathrm{c}}$ is very much dependent on the mobilized angle of shearing [57]. For a particular stress level, soil with higher density is always associated with higher mobilized angle of shearing [57]. In this study, the $D_{\mathrm{r}}$ values were estimated from the cone penetration resistance values measured by using the empirical relationship proposed by Jamiolkowski et al. [58], which was obtained from the calibration chamber tests carried out in uncemented, NC quartz sand, taking into consideration the influence of the effective vertical stress as:

$D_{\mathrm{r}}=-98+66 \times \log \left(\frac{q_{c}}{\sqrt{\sigma_{\mathrm{vo}}^{\prime}}}\right)$

where $D_{\mathrm{r}}$ is the relative density in percentage and $\sigma_{\mathrm{vo}}^{\prime}$ is the effective vertical stress in the same units as, $q_{\mathrm{c}}$. Bolton and Gui [57] state that Eq. (4) overestimates and underestimates the $D_{\mathrm{r}}$ values, by approximately 10 and $20 \%$, respectively, for a particular depth. Cai et al. [59] state that in general Eq. (4) is acceptable for NC soils, while for OC deposits, the value of $\sigma_{\mathrm{vo}}^{\prime}$ must be replaced by horizontal effective stress $\sigma_{\mathrm{vo}}^{\prime}$.

The soil hydraulic conductivity $\left(k_{\mathrm{h}}\right)$ was obtained in the field by both pore pressure dissipation tests and direct push permeability tests at depth intervals of $1.0 \mathrm{~m}$. From the pore pressure dissipation tests, the monotonically decreasing pore water pressure dissipation curves were obtained at clayey silt layers. The recorded times for $50 \%$ pore pressure dissipation $\left(t_{50}\right)$ were assessed by theoretical solutions presented by Teh and Houlsby [60]. The measured $t_{50}$ was used in conjunction with the empirical correlation proposed by Parez and Fauriel [61] to deduce the horizontal hydraulic conductivity. However, at sands and silty sand layers, the measured pore water pressures were almost hydrostatic. The recorded times for $50 \%$ pore pressure dissipation were $<60 \mathrm{~s}$, with some less than $1 \mathrm{~s}$. It was difficult to record the dissipation time accurately at these depths. Therefore, the measurements from dissipation tests were used to find the hydraulic conductivity of the clayey silts. For the levels where we observed the sands and silty sands, the other testing method, which is the direct 
Fig. 1 Area view of test profile locations on the northern coast of Izmir Gulf in Turkey [29]

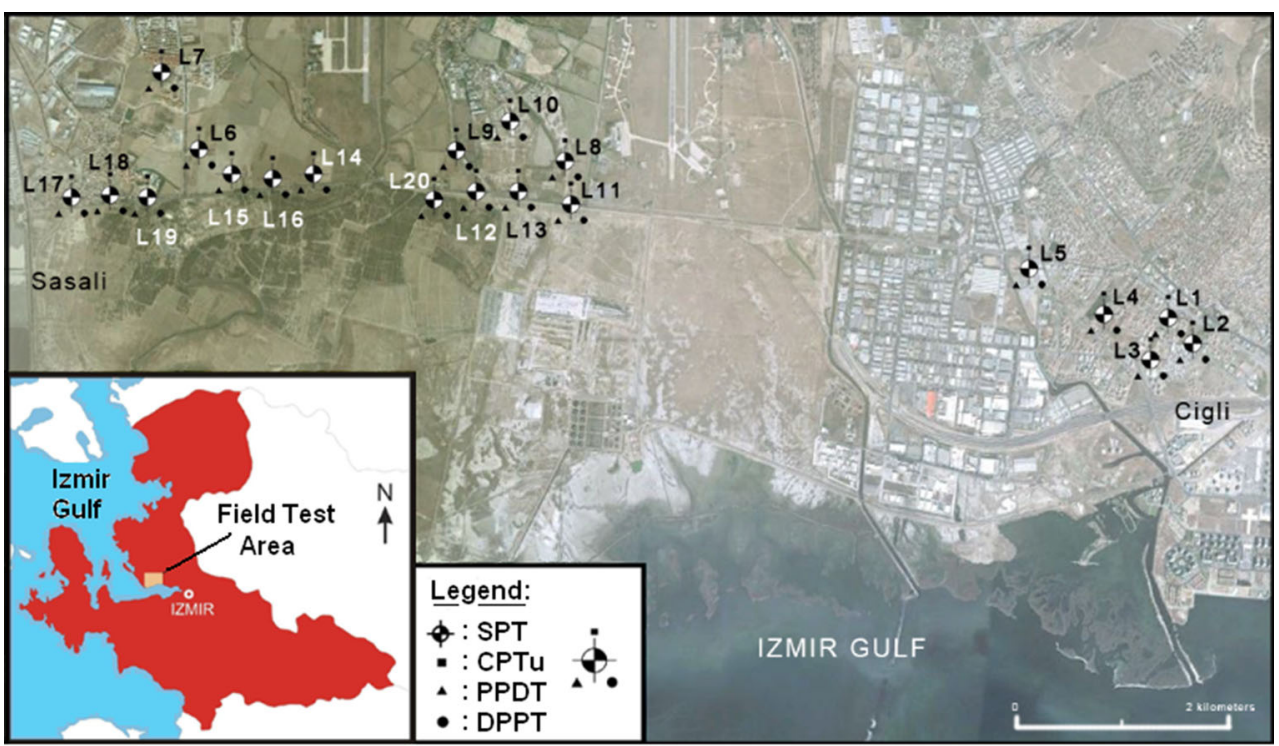

Note: SPT $=$ Standard Penetration Test, $\mathrm{CPTu}=$ Piezocone Penetration Test, DPPT $=$ Direct Push Permeability Test, PPDT $=$ Pore Pressure Dissipation Test push permeability test, is likely to provide reliable results. Hydraulic conductivity from direct push permeability test was recovered from the applied excess head, $\Delta h$, and measured volumetric flow, $Q$, through the spherical form of Darcy's law [62]:

$k_{\mathrm{h}}=\frac{Q}{4 \pi \Delta h a_{\mathrm{s}}}$

where $a_{\mathrm{s}}$ is the effective radius of the spherical injection zone, which is calculated as $1.44 \mathrm{~cm}$ in this study.

The coefficient of consolidation of soils throughout the depths was determined by using the equation given below:

$c_{\mathrm{h}}=\frac{k_{\mathrm{h}}}{m_{\mathrm{v}} \gamma_{\mathrm{w}}}$

where $\gamma_{\mathrm{w}}$ is the unit weight of water and $m_{v}$ is the compressibility of the soil estimated from the CPTu tests based on the correlation proposed by Robertson [63]:

$m_{v}=\frac{1}{\alpha_{M}\left(q_{t}-\sigma_{\mathrm{vo}}\right)}$

where $\sigma_{\mathrm{vo}}$ is the in situ total vertical stress, $q_{t}$ is the corrected total cone resistance, and $\alpha_{M}$ varies with the soil behavior type index $\left(I_{\mathrm{c}}\right)$ [as given by Eq. (8)] modified by Robertson and Wride [64].

$I_{\mathrm{c}}=\left[\left(3.47-\log _{10} q_{c 1 N}\right)^{2}+\left(\log _{10} F+1.22\right)^{2}\right]^{0.5}$

where $q_{c 1 N}$ is the normalized cone penetration resistance given in Eq. (1) and $F$ is normalized friction resistance in percent given in Eq. (2).

$$
\begin{aligned}
& \text { If } I_{\mathrm{c}}>2.2 \text { and } q_{c 1 N}<14 \text {, use } \alpha_{M}=q_{c 1 N} . \\
& \text { If } I_{\mathrm{c}}>2.2 \text { and } q_{c 1 N}>14 \text {, use } \alpha_{M}=14 . \\
& \text { If } I_{\mathrm{c}}<2.2 \text {, use } \alpha_{M}=0.03\left[10^{\left(0.55 I_{\mathrm{c}}+1.68\right)}\right] .
\end{aligned}
$$

The disturbed soil samples were procured at a depth interval of $1.5 \mathrm{~m}$ by SPT spoon in order to find the fines content (FC) of the samples. In total, 64 soil samples from 20 boreholes were classified in the laboratory.

The cone penetration resistance, coefficient of consolidation, and relative density recorded with field tests. Fines content obtained from the laboratory tests. The results of these tests were used first to find the effects of fines and relative density on the cone penetration resistance of the silty sands. Figure 2 a illustrates the variation of the coefficient of consolidation with fines content for four individual ranges of relative densities [29]. Figure $2 b$ illustrates the variation of measured normalized cone penetration resistance values with log normalized penetration rate $\left(V=v d / c_{\mathrm{h}}\right)$ for six distinct ranges of relative density [29] where $v$ is the rate of penetration and $d$ is the diameter of the cone. In this figure, the normalized penetration rate was changed only due to the change in the coefficient of consolidation of the soil layers. The coefficient of consolidation values obtained for each $D_{\mathrm{r}}$ and FC from Fig. 2a and normalized cone penetration resistance values obtained for each $D_{\mathrm{r}}$ and $V\left(=v d / c_{\mathrm{h}}\right)$ from Fig. 2b are given in Table 1, [29]. As given in the table for each given relative density, $q_{c 1 N}, c_{\mathrm{h}}$, and $V$ are determined for nine different fines content from 0 to $40 \%$. 


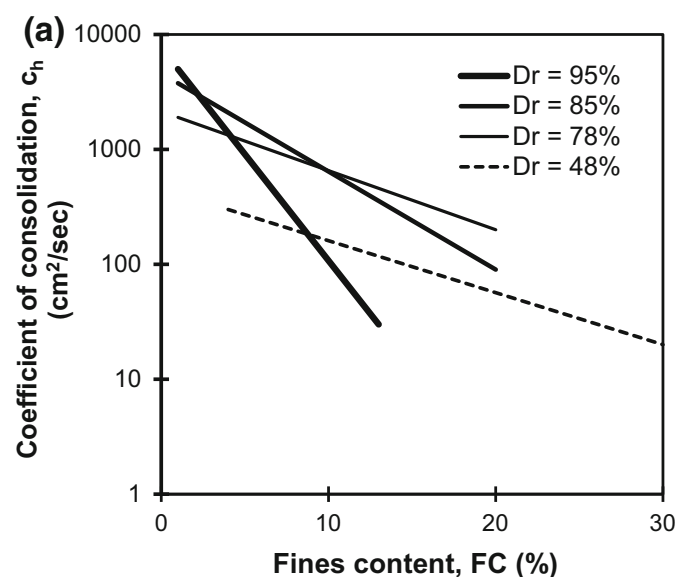

(b)

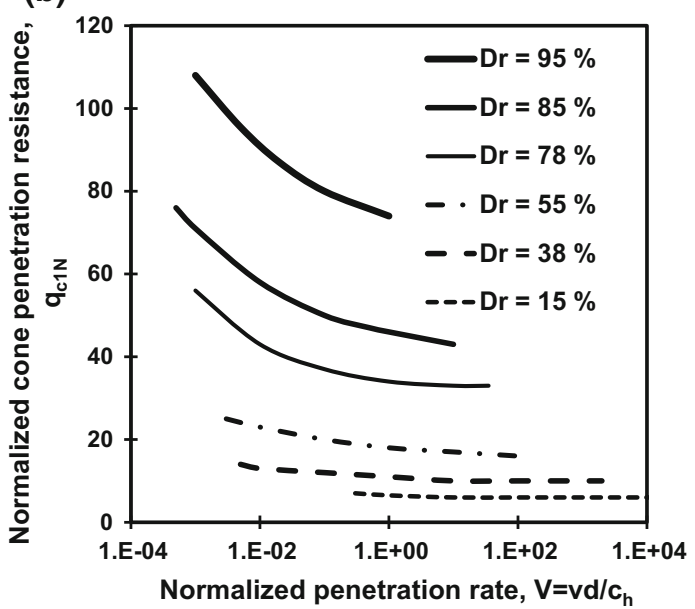

Fig. 2 Change in a coefficient of consolidation with fines content at different relative densities and $\mathbf{b}$ normalized cone penetration resistance with normalized penetration rate at different relative densities [29]

\section{Artificial neural network model}

In this work, an ANN model was developed to predict the normalized cone penetration resistance of silty sands. Three factors affecting the cone penetration resistance are presented to the ANN as model input variables. These include the relative density $\left(D_{\mathrm{r}}\right)$, fines content $(\mathrm{FC})$, and the horizontal coefficient of consolidation $\left(c_{\mathrm{h}}\right)$. The normalized cone penetration resistance $\left(q_{c l N}\right)$ was the single output parameter. The data used to train and validate the ANN model were obtained from the field tests as mentioned earlier in Sect. 2. As recommended by Masters [65] and detailed by Shahin et al. [52], the available data were then randomly separated into two statistically consistent sets: a training set to construct the neural network model and an independent validation set to determine model performance in the deployed environment. Therefore, in total, $80 \%$ of the data were utilized for training and $20 \%$ for validation. The statistics of the data used for the training and validation sets are given in Table 2, which include the minimum, maximum, mean, and standard deviation.

In this work, the optimal model geometry was obtained by using a trial-and-error approach. It should be noticed that a network with one hidden layer can approximate any continuous function, provided that sufficient connection weights are utilized [66]. Therefore, one hidden layer was used in the current work while developing the ANN model. The optimum number of neurons in the hidden layer was detected by varying their number by starting with a minimum of 1 and then increasing the network size in steps by adding 1 neuron each time. Two different transfer functions (log-sigmoid [67] and tan-sigmoid [36]) were used in the hidden and output layers to achieve the best performance in training as well as in validation. Two momentum factors, $\mu$ $(=0.01$ and 0.001 ), were chosen for the training process to search for the most efficient ANN architecture. The neural network toolbox of MATLAB7.0, a well-known numerical computation and visualization software [68], was employed for training and validation of MLPs. Training started with a small number of epochs $(=50)$ and kept on incrementing by 50 epochs until the onset of specialized training as reflected in the reversal of the downward trend of the error for validation data. The maximum number of epochs to train was chosen as 500. The coefficient of determination, $R^{2}$, and the mean absolute error, MAE, were used to assess the performance of the developed ANN models. In order to decide the optimum network geometry, the performance of the network during the training and validation processes was investigated for each network size until no significant improvement in the error took place.

The details of the optimal performance of the networks are presented in Table 3. Table 3 indicates that ANN with three hidden neurons yielded the maximum $R^{2}$ of 0.9971 and the minimum MAE of 1.46 in the validation phase. Thus, it was selected as the best ANN model. Connection weights and biases of the final model are given in Table 4 .

\section{Results and discussion}

The $q_{c I N}$ values obtained from the ANN model were compared with the measured $q_{c I N}$ values in Figs. 3 and 4 for training and validation sets, respectively. It can be seen that the ANN model has the minimum scatter around the line of equality between the measured and predicted $q_{c I N}$ values. The model also has high coefficients of determination $\left(R^{2}\right)$ in the training and validation samples. This shows that the ANN model is able to predict cone penetration resistances of silty sands, if the soil properties $\left(D_{\mathrm{r}}\right.$, $\mathrm{FC}$, and $c_{\mathrm{h}}$ ) are known.

In point of fact, the coefficient of correlation between the measured and predicted values is a good indicator to 
Table 1 Summary of field and laboratory test results [29]

\begin{tabular}{|c|c|c|c|c|}
\hline $\begin{array}{l}1 \\
\text { Relative } \\
\text { density } \\
\left(D_{\mathrm{r}}\right)\end{array}$ & $\begin{array}{l}2 \\
\text { Fines } \\
\text { content } \\
\text { (FC) }\end{array}$ & $\begin{array}{l}3 \\
\text { Coefficient of } \\
\text { consolidation } \\
\left(c_{\mathrm{h}}\right)\end{array}$ & $\begin{array}{l}4 \\
\text { Normalized } \\
\text { penetration } \\
\text { rate } \\
\left(V=v d / c_{\mathrm{h}}\right)\end{array}$ & $\begin{array}{l}5 \\
\text { Normalized } \\
\text { penetration } \\
\text { resistance } \\
\left(q_{c I N}\right)\end{array}$ \\
\hline$\%$ & $\%$ & $\mathrm{~cm} / \mathrm{s}$ & & \\
\hline \multirow[t]{9}{*}{30} & 0 & $2.00 \mathrm{E}+02$ & $3.60 \mathrm{E}-02$ & 6.3 \\
\hline & 5 & $1.68 \mathrm{E}+02$ & $4.29 \mathrm{E}-02$ & 6.3 \\
\hline & 10 & $1.41 \mathrm{E}+02$ & $5.11 \mathrm{E}-02$ & 6.3 \\
\hline & 15 & $1.18 \mathrm{E}+02$ & $6.09 \mathrm{E}-02$ & 6.3 \\
\hline & 20 & $9.93 \mathrm{E}+01$ & $7.25 \mathrm{E}-02$ & 6.2 \\
\hline & 25 & $8.34 \mathrm{E}+01$ & $8.64 \mathrm{E}-02$ & 6.2 \\
\hline & 30 & $7.00 \mathrm{E}+01$ & $1.03 \mathrm{E}-01$ & 6.2 \\
\hline & 35 & $5.88 \mathrm{E}+01$ & $1.23 \mathrm{E}-01$ & 6.2 \\
\hline & 40 & $4.93 \mathrm{E}+01$ & $1.46 \mathrm{E}-01$ & 6.2 \\
\hline \multirow[t]{9}{*}{38} & 0 & $4.55 E+02$ & $1.58 \mathrm{E}-02$ & 13.0 \\
\hline & 5 & $2.71 \mathrm{E}+02$ & $2.66 \mathrm{E}-02$ & 12.5 \\
\hline & 10 & $1.61 \mathrm{E}+02$ & $4.48 \mathrm{E}-02$ & 12.2 \\
\hline & 15 & $9.56 \mathrm{E}+01$ & $7.53 \mathrm{E}-02$ & 12.0 \\
\hline & 20 & $5.68 \mathrm{E}+01$ & $1.27 \mathrm{E}-01$ & 11.8 \\
\hline & 25 & $3.38 \mathrm{E}+01$ & $2.13 \mathrm{E}-01$ & 11.5 \\
\hline & 30 & $2.01 \mathrm{E}+01$ & $3.58 \mathrm{E}-01$ & $11 . .3$ \\
\hline & 35 & $1.19 \mathrm{E}+01$ & $6.03 \mathrm{E}-01$ & 11.0 \\
\hline & 40 & $7.10 \mathrm{E}+00$ & $1.01 \mathrm{E}+00$ & 11.0 \\
\hline \multirow[t]{9}{*}{55} & 0 & $4.55 \mathrm{E}+02$ & $1.58 \mathrm{E}-02$ & 22.5 \\
\hline & 5 & $2.71 \mathrm{E}+02$ & $2.66 \mathrm{E}-02$ & 21.5 \\
\hline & 10 & $1.61 \mathrm{E}+02$ & $4.48 \mathrm{E}-02$ & 21.0 \\
\hline & 15 & $9.56 \mathrm{E}+01$ & $7.53 \mathrm{E}-02$ & 20.0 \\
\hline & 20 & $5.69 \mathrm{E}+01$ & $1.27 \mathrm{E}-01$ & 19.5 \\
\hline & 25 & $3.38 \mathrm{E}+01$ & $2.13 \mathrm{E}-01$ & 18.0 \\
\hline & 30 & $2.01 \mathrm{E}+01$ & $3.58 \mathrm{E}-01$ & 17.0 \\
\hline & 35 & $1.19 \mathrm{E}+01$ & $6.03 \mathrm{E}-01$ & 15.2 \\
\hline & 40 & $7.10 \mathrm{E}+00$ & $1.01 \mathrm{E}+00$ & 15.0 \\
\hline \multirow[t]{9}{*}{78} & 0 & $2.14 \mathrm{E}+04$ & $3.36 \mathrm{E}-04$ & 50.0 \\
\hline & 5 & $1.19 \mathrm{E}+04$ & $6.07 \mathrm{E}-04$ & 47.0 \\
\hline & 10 & $6.58 \mathrm{E}+03$ & $1.10 \mathrm{E}-03$ & 44.0 \\
\hline & 15 & $3.64 \mathrm{E}+03$ & $1.98 \mathrm{E}-03$ & 41.0 \\
\hline & 20 & $2.02 \mathrm{E}+03$ & $3.56 \mathrm{E}-03$ & 39.0 \\
\hline & 25 & $1.12 \mathrm{E}+03$ & $6.43 \mathrm{E}-03$ & 37.0 \\
\hline & 30 & $6.21 \mathrm{E}+02$ & $1.16 \mathrm{E}-02$ & 36.0 \\
\hline & 35 & $3.44 \mathrm{E}+02$ & $2.09 \mathrm{E}-02$ & 35.0 \\
\hline & 40 & $1.91 \mathrm{E}+02$ & $3.77 \mathrm{E}-02$ & 34.0 \\
\hline \multirow[t]{9}{*}{85} & 0 & $4.59 \mathrm{E}+03$ & $1.57 \mathrm{E}-03$ & 69.0 \\
\hline & 5 & $1.71 \mathrm{E}+03$ & $4.20 \mathrm{E}-03$ & 62.0 \\
\hline & 10 & $6.40 \mathrm{E}+02$ & $1.12 \mathrm{E}-02$ & 57.0 \\
\hline & 15 & $2.39 \mathrm{E}+02$ & $3.01 \mathrm{E}-02$ & 54.0 \\
\hline & 20 & $8.93 \mathrm{E}+01$ & $8.07 \mathrm{E}-02$ & 51.0 \\
\hline & 25 & $3.33 \mathrm{E}+01$ & $2.16 \mathrm{E}-01$ & 49.0 \\
\hline & 30 & $1.24 \mathrm{E}+01$ & $5.78 \mathrm{E}-01$ & 47.0 \\
\hline & 35 & $4.65 \mathrm{E}+00$ & $1.55 \mathrm{E}+00$ & 45.0 \\
\hline & 40 & $1.74 \mathrm{E}+00$ & $4.15 \mathrm{E}+00$ & 43.0 \\
\hline
\end{tabular}

Table 1 continued

\begin{tabular}{|c|c|c|c|c|}
\hline $\begin{array}{l}1 \\
\text { Relative } \\
\text { density } \\
\left(D_{\mathrm{r}}\right) \\
\%\end{array}$ & $\begin{array}{l}2 \\
\text { Fines } \\
\text { content } \\
(\mathrm{FC}) \\
\%\end{array}$ & $\begin{array}{l}3 \\
\text { Coefficient of } \\
\text { consolidation } \\
\left(c_{\mathrm{h}}\right) \\
\mathrm{cm} / \mathrm{s}\end{array}$ & $\begin{array}{l}4 \\
\text { Normalized } \\
\text { penetration } \\
\text { rate } \\
\left(V=v d / c_{\mathrm{h}}\right) \\
-\end{array}$ & $\begin{array}{l}5 \\
\text { Normalized } \\
\text { penetration } \\
\text { resistance } \\
\left(q_{c I N}\right) \\
-\end{array}$ \\
\hline \multirow[t]{8}{*}{95} & 0 & $7.66 \mathrm{E}+03$ & $9.40 \mathrm{E}-04$ & 107.0 \\
\hline & 5 & $9.10 \mathrm{E}+02$ & $7.91 \mathrm{E}-03$ & 95.0 \\
\hline & 10 & $1.08 \mathrm{E}+02$ & $6.66 \mathrm{E}-02$ & 87.0 \\
\hline & 15 & $1.29 \mathrm{E}+01$ & $5.60 \mathrm{E}-01$ & 81.0 \\
\hline & 20 & $1.53 \mathrm{E}+00$ & $4.71 \mathrm{E}+00$ & 75.0 \\
\hline & 25 & $1.82 \mathrm{E}-01$ & $3.97 \mathrm{E}+01$ & 70.0 \\
\hline & 30 & $2.16 \mathrm{E}-02$ & $3.34 \mathrm{E}+02$ & 66.0 \\
\hline & 35 & $2.56 \mathrm{E}-03$ & $2.81 \mathrm{E}+03$ & 63.0 \\
\hline
\end{tabular}

examine the prediction performance of the model [69]. In this work, variance VAF, represented by Eq. (9), and the root mean square error RMSE, represented by Eq. (10), were also calculated to determine the performance of the developed model, as employed by Grima and Babuska [41], Finol et al. [70], Gokceoglu [71], Erzin [7], and Erzin et al. [9, 47, 48]

$$
\begin{aligned}
& \mathrm{VAF}=\left[1-\frac{\operatorname{var}(y-\hat{y})}{\operatorname{var}(y)}\right] \times 100 \\
& \mathrm{RMSE}=\sqrt{\frac{1}{N} \sum_{i=1}^{N}\left(y_{i}-\hat{y}_{i}\right)^{2}}
\end{aligned}
$$

where var denotes the variance, $y$ is the measured value, $\hat{y}$ is the predicted value, and $N$ is the number of the sample. If VAF is $100 \%$ and RMSE is 0 , the model is treated as excellent.

Values of VAF and RMSE for the ANN model developed are given in Table 5. Table 5 shows that the ANN model developed exhibits high prediction performance based on the performance indices, which demonstrates its usefulness and efficiency.

In addition to the performance indices, a graph between the scaled percent error, SPE [as given by Eq. (11) and employed by Kanibir et al. [72]; Erzin and Cetin [16]], and the cumulative frequency was also drawn for the ANN model (Fig. 5) to further examine the prediction performance of the model.

$\mathrm{SPE}=\frac{\left(\left(q_{c 1 N}\right)_{\mathrm{p}}-\left(q_{c 1 N}\right)_{m}\right)}{\left(\left(\left(q_{c 1 N}\right)_{m}\right)_{\max }-\left(\left(q_{c 1 N}\right)_{m}\right)_{\min }\right)}$

where $\left(q_{c 1 N}\right)_{\mathrm{p}}$ and $\left(q_{c 1 N}\right)_{m}$ are the predicted and the measured $q_{c l N}$ values; and $\left(\left(q_{c 1 N}\right)_{m}\right)_{\max }$ and $\left(\left(q_{c 1 N}\right)_{m}\right)_{\min }$ are the maximum and minimum measured $q_{c l N}$ values, 
Table 2 Statistics of the data used for the ANN model developed

\begin{tabular}{lccrr}
\hline Parameters used & Minimum & Maximum & Mean & Std. deviation \\
\hline Input parameters & & & & \\
$D_{\mathrm{r}}(\%)$ & 30 & 95 & 62.9057 & 24.24813 \\
FC $(\%)$ & 0 & 40 & 19.6226 & 12.85455 \\
$c_{\mathrm{h}}\left(\mathrm{cm}^{2} / \mathrm{s}\right)$ & 0.00256 & 21,398 & 1264.2016 & 3565.31315 \\
Output parameter & & & & \\
$q_{\text {clN }}$ & 6.19 & 107 & 34.2670 & 26.61560 \\
\hline
\end{tabular}

Table 3 Details of the optimal performance of networks in predicting $q_{c I N}$

\begin{tabular}{|c|c|c|c|c|c|c|c|c|}
\hline \multirow{2}{*}{$\begin{array}{l}\text { Number of neurons } \\
\text { in the hidden layer }\end{array}$} & \multicolumn{2}{|l|}{ Transfer function in } & \multirow[t]{2}{*}{$\mu$} & \multirow[t]{2}{*}{ Number of epochs } & \multicolumn{2}{|c|}{ Training } & \multicolumn{2}{|l|}{ Testing } \\
\hline & Neurons of the hidden layer & Neurons of the output layer & & & $R^{2}$ & MAE & $R^{2}$ & MAE \\
\hline 1 & Tan-sigmoid & Tan-sigmoid & 0.001 & 170 & 0.9824 & 4.04 & 0.9743 & 3.30 \\
\hline 2 & Tan-sigmoid & Tan-sigmoid & 0.001 & 19 & 0.9956 & 3.62 & 0.9958 & 1.48 \\
\hline 3 & Tan-sigmoid & Tan-sigmoid & 0.001 & 8 & 0.9963 & 3.31 & 0.9971 & 1.46 \\
\hline
\end{tabular}

Table 4 Connection weights and biases of the best ANN model

\begin{tabular}{|c|c|c|c|c|c|c|}
\hline \multirow[t]{3}{*}{ Hidden neuron } & \multicolumn{4}{|l|}{ Weights } & \multicolumn{2}{|l|}{ Bias } \\
\hline & \multicolumn{2}{|c|}{ Input neurons } & \multicolumn{2}{|c|}{ Output neuron } & \multirow[b]{2}{*}{ Hidden layer } & \multirow[b]{2}{*}{ Output layer } \\
\hline & $D_{\mathrm{r}}(\%)$ & $\mathrm{FC}(\%)$ & $c_{\mathrm{h}}\left(\mathrm{cm}^{2} / \mathrm{s}\right)$ & $q_{c I N}$ & & \\
\hline 1 & 1.84280 & -0.34393 & 0.27399 & 1.7344 & -2.28770 & -0.31883 \\
\hline 2 & -0.83467 & 0.11234 & 0.26878 & -1.8861 & -0.59476 & \\
\hline 3 & -0.40448 & 1.94970 & 0.67043 & -0.015031 & 1.02250 & \\
\hline
\end{tabular}

respectively. Figure 5 shows that about $92 \%$ of $q_{c 1 N}$ values predicted from the ANN model developed are between $+2 \%$ and $-6 \%$ of the SPE, which indicates a perfect estimate for the $q_{c 1 N}$ value of the soil. From here, it can be concluded that the $q_{c 1 N}$ value of soil could be predicted from three soil parameters $\left(D_{\mathrm{r}}, \mathrm{FC}\right.$, and $\left.c_{\mathrm{h}}\right)$ using trained ANNs values, with acceptable accuracy.

Neural network applications are generally treated as black box applications [73, 74]. Some researchers (Cabalar and Cevik [73]; Cevik et al. [74]; Köroğlu et al. [75]; Erzin and Ecemis [26]) opened this black box and introduced the NN application in a closed-form solution by utilizing the related NN parameters such as weights and biases. Similarly, the ANN model developed in this study can be expressed in explicit function form using the related NN parameters. Using the weights and biases of the optimal ANN model (Table 3 ), normalized cone penetration resistance $\left(q_{c 1 N}\right)$ can be expressed in terms of relative density $\left(D_{\mathrm{r}}\right)$, fines content (FC), and horizontal coefficient of consolidation $\left(c_{\mathrm{h}}\right)$ as follows:

$q_{c 1 N}=(\tan \operatorname{sig} W+0.9) \times 56+6.19$

where $\tan \operatorname{sig}(x)=2 /\left(1+\mathrm{e}^{-2 x}\right)-1$ and finally output is computed as:

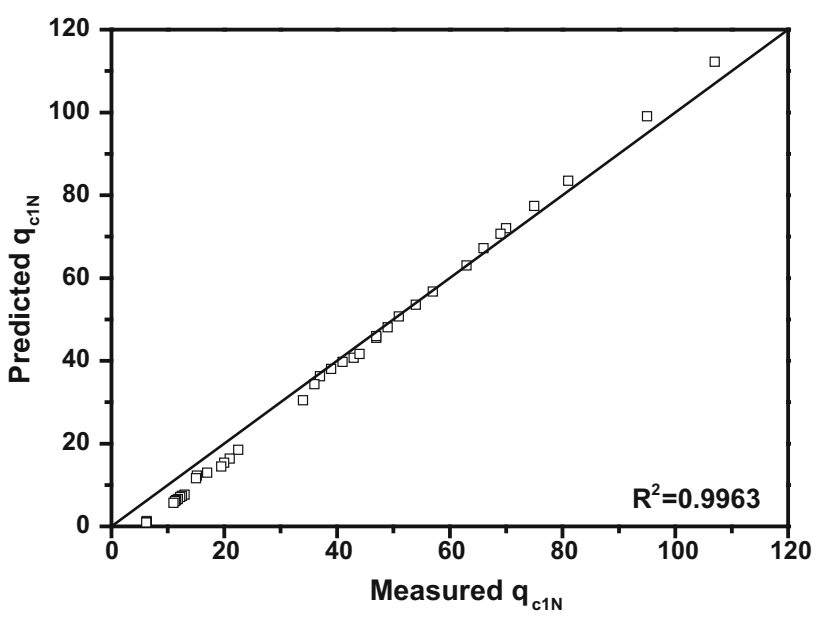

Fig. 3 Comparison of the $q_{c I N}$ values obtained from field tests with the $q_{c I N}$ values predicted from the ANN model for training samples

$$
\begin{aligned}
\mathrm{W}= & {\left[1.7344 \times \tan \operatorname{sig} U_{1}-1.8861 \times \tan \operatorname{sig} U_{2}-0.015031\right.} \\
& \left.\times \tan \operatorname{sig} U_{3}\right]-0.31383 \\
U_{1}= & 1.84280 \times D_{\mathrm{r}}-034393 \times F C+0.27399 \times c_{\mathrm{h}} \\
& -2.28770
\end{aligned}
$$




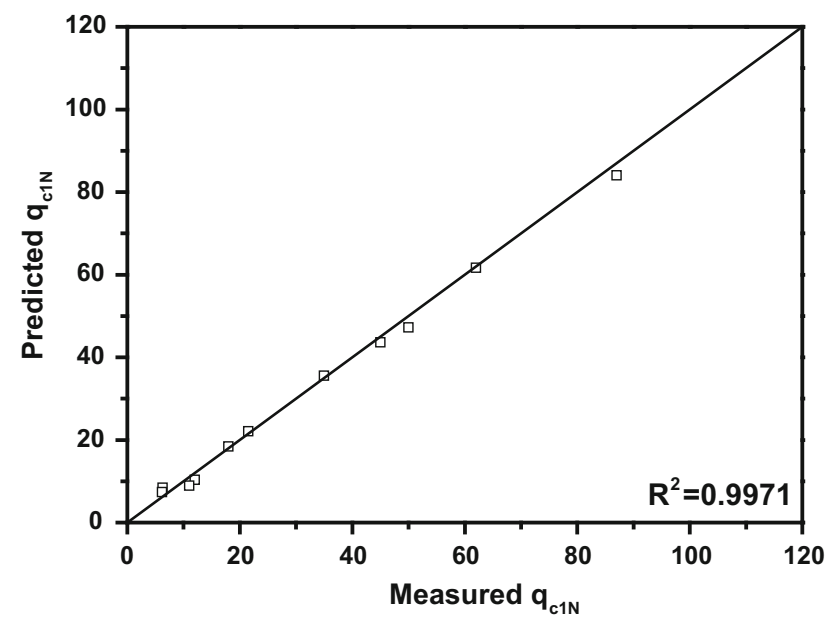

Fig. 4 Comparison of the $q_{c l N}$ values calculated from field tests with the $q_{c I N}$ values predicted from the ANN model for validation samples

Table 5 Performance indices $\left(R^{2}\right.$, RMSE, MAE and VAF) of the ANN model developed

\begin{tabular}{lllll}
\hline Data & $R^{2}$ & RMSE & MAE & VAF (\%) \\
\hline Training set & 0.9963 & 3.88 & 3.31 & 99.12 \\
Validation set & 0.9971 & 1.71 & 1.46 & 99.59 \\
\hline
\end{tabular}

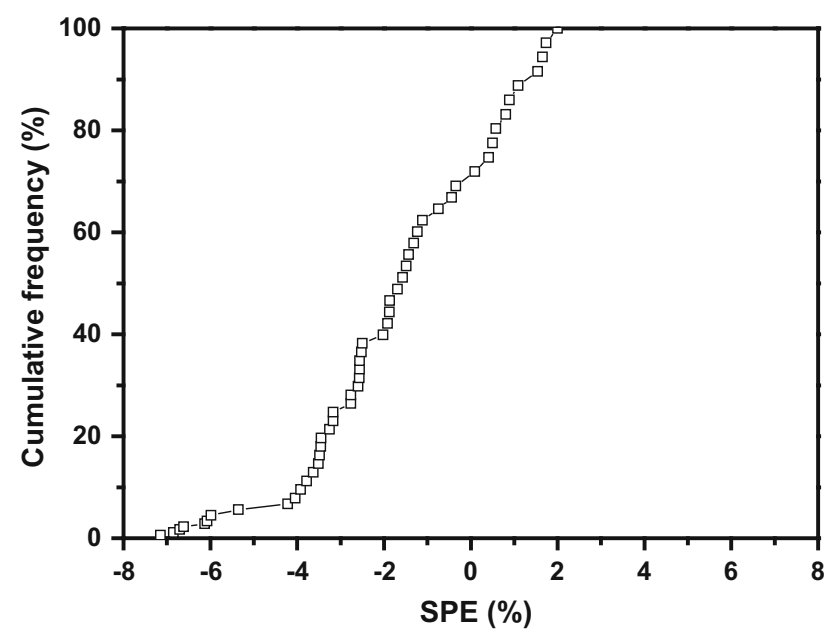

Fig. 5 Relationship between the scaled percent error and cumulative frequency

$$
\begin{aligned}
U_{2}= & -0.83467 \times D_{\mathrm{r}}+0.11234 \times F C \\
& +0.26878 \times c_{\mathrm{h}}-0.59476 \\
U_{3}= & -0.41 .022500448 \times D_{\mathrm{r}}+1.94970 \times F C \\
& +0.67043 \times c_{\mathrm{h}}+1.02250
\end{aligned}
$$

It should be noted that the proposed ANN model in this work is valid for the ranges of parameters given in Table 2 .

\section{Conclusions}

In this study, an ANN model that can be used for predicting cone penetration resistance of silty sands has been developed. For this purpose, the results of three high-quality field tests (CPTu, PPDT, and DPPT) performed at 20 different locations on the northern coast of the Izmir Gulf in Turkey have been used in the ANN model. The ANN model consisted of three input parameters (relative density, fines content, and horizontal coefficient of consolidation) and a single output parameter (normalized cone penetration resistance). It has been demonstrated that the ANN model is efficient in determining the cone penetration resistance of silty sands and yields cone penetration resistance values that are very close to those obtained from the field tests. The ANN model exhibits high prediction performance based on the performance indices, which demonstrates its usefulness and efficiency.

Acknowledgments The data from this study were from the European Union Marie Curie Fellowship under Grant No. IRG248218 and TUBITAK Project No. 111M602. The authors wish to thank Research Assistant Mustafa Karaman for his assistance in conducting field tests.

\section{References}

1. Kim D, Shin Y, Siddiki N (2010) Geotechnical design based on CPT and PMT. Publication FHWA/IN/JTRP-2010/07. Joint Transportation Research Program, Indiana Department of Transportation and Purdue University, West Lafayette. Indiana. doi: $10.5703 / 1288284314264$

2. Robertson PK, Cabal KL (2010) Guide to cone penetration testing for geotechnical engineering, 3rd edn. Gregg Drilling and Testing, Signal Hill

3. Park HI, Kim YT (2011) Prediction of strength of reinforced lightweight soil using an artificial neural network. Eng Comput Int J Comput Aid Eng Softw 28(5):600-605

4. Fausett LV (1994) Fundamentals of neural networks: architecture, algorithms, and applications. Prentice-Hall, Englewood Cliffs

5. Najjar YM, Ali HE (1999) Simulating the stress-strain behavior of Nevada sand by ANN. In: Proceedings of the 5th U.S. national congress on computational mechanics (USACM), Boulder, CO

6. Penumadu D, Zhao R (1999) Triaxial compression behavior of sand and gravel using and artificial neural networks (ANN). Comput Geotech 24(3):207-230

7. Erzin Y (2007) Artificial neural networks approach for swell pressure versus soil suction behavior. Can Geotech J 44(10):1215-1223

8. Ozer M, Isik NS, Orhan M (2008) Statistical and neural network assessment of the compression index of clay-bearing soils. Bull Eng Geol Environ 67:537-545

9. Erzin Y, Gumaste SD, Gupta AK, Singh DN (2009) ANN models for determining hydraulic conductivity of compacted fine grained soils. Can Geotech J 46:955-968

10. Das SK, Basudhar PK (2006) Undrained lateral load capacity of piles in clay using artificial neural network. Comput Geotech 33:454-459 
11. Park HI, Cho CH (2010) Neural network model for predicting the resistance of driven piles. Mar Georesourc Geotech 28(4):324-344

12. Zhao HB (2008) Slope reliability analysis using a support vector machine. Comput Geotech 35:459-467

13. Cho SE (2009) Probabilistic stability analyses of slopes using the ANN-based response surface. Comput Geotech 36:787-797

14. Erzin Y, Cetin T (2012) The use of neural networks for the prediction of the critical factor of safety of an artificial slope subjected to earthquake forces. Sci Iran 19(2):188-194

15. Erzin Y, Cetin T (2013) The prediction of the critical factor of safety of homogeneous finite slopes using neural networks and multiple regressions. Comput Geosci 51:305-313

16. Erzin Y, Cetin T (2014) The prediction of the critical factor of safety of homogeneous finite slopes subjected to earthquake forces using neural networks and multiple regressions. Int $\mathbf{J}$ Geomech Eng 6(1):1-15

17. Shahin MA, Jaksa MB, Maier HR (2005) Stochastic simulation of settlement prediction of shallow foundations based on a deterministic artificial neural network model. In: Proceedings of the international congress on modelling and simulation, MODSIM 2005, Melbourne, Australia, pp 73-78

18. Erzin Y, Gul T (2013) The use of neural networks for the prediction of the settlement of pad footings on cohesionless soils based on standard penetration test. Int $\mathbf{J}$ Geomech Eng 5(6):541-564

19. Erzin Y, Gul T (2014) The use of neural networks for the prediction of the settlement of one-way footings on cohesionless soils based on standard penetration test. Neural Comput Appl 24:891-900

20. Goh ATC (2002) Probabilistic neural network for evaluating seismic liquefaction potential. Can Geotech J 39:219-223

21. Baziar MH, Nilipour N (2003) Evaluation of liquefaction potential using neural-networks and CPT results. Soil Dyn Earthq Eng 23:631-636

22. Hanna AM, Ural D, Saygili G (2007) Neural network model for liquefaction potential in soil deposits using Turkey and Taiwan earthquake data. Soil Dyn Earthq Eng 27(6):521-540

23. Pathak SR, Dalvi AN (2011) Performance of empirical models for assessment of seismic soil liquefaction. Int J Earth Sci Eng 4:83-86

24. Kumar V, Venkatesh K, Tiwari RP, Kumar Y (2012) Application of ANN to predict liquefaction potential. Int J Comput Eng Sci 2(2):379-389

25. Venkatesh K, Kumar V, Tiwari R (2013) Appraisal of liquefaction potential using neural networks and neuro fuzzy approach. Appl Artif Intel 27(8):700-720

26. Erzin Y, Ecemis N (2015) The use of neural networks for CPTbased liquefaction screening. Bull Eng Geol Environ 74:103-116

27. Shi JJ (2000) Reduction prediction error by transforming input data for neural networks. J Comput Civil Eng 14(2):109-116

28. Yoo C, Kim J-M (2007) Tunneling performance prediction using an integrated GIS and neural network. Comput Geotech 34:19-30

29. Ecemis N, Karaman M (2014) Influence of non-/low plastic fines on cone penetration and liquefaction resistance. Eng Geol 181:48-57

30. Shahin M (2010) Intelligent computing for modeling axial capacity of pile foundations. Can Geotech J 47(2):230-243

31. Zurada JM (1992) Introduction to artificial neural systems. West, St. Paul

32. Hecht-Nielsen R (1987) Kolomogorov's mapping neural network existence theorem. In: Proceedings of the first IEEE international conference on neural networks, San Diego, CA, USA, pp 11-14

33. Maren A, Harston C, Pap R (1990) Handbook of neural computing applications. Academic Press, San Diego
34. Ripley BD (1996) Pattern recognition and neural networks. Cambridge University Press, Cambridge

35. Goh ATC (1994) Seismic liquefaction potential assessed by neural networks. J Geotech Geoenviron 120(9):1467-1480

36. Orbanić P, Fajdiga M (2003) A neural network approach to describing the fretting fatigue in aluminum-steel couplings. Int $\mathbf{J}$ Fatigue 25:201-207

37. Sonmez H, Gokceoglu C, Nefeslioglu HA, Kayabasi A (2005) Estimation of rock modulus: For intact rocks with an artificial neural network and for rock masses with a new empirical equation. Int J Rock Mech Min 43(2):224-235

38. Hush DR (1989) Classification with neural networks: a performance analysis. In: Proceedings of the IEEE international conference on systems engineering, Dayton, OH, USA, pp 277-280

39. Kaastra I, Boyd M (1996) Designing a neural network for forecasting financial and economic time series. Neurocomputing 10(3):215-236

40. Kanellopoulas I, Wilkinson GG (1997) Strategies and best practice for neural network image classification. Int J Remote Sens 18:711-725

41. Grima MA, Babuska R (1999) Fuzzy model for the prediction of unconfined compressive strength of rock samples. Int $\mathrm{J}$ Rock Mech Min 36:339-349

42. Haque ME, Sudhakar KV (2002) ANN back-propagation prediction model for fracture toughness in microalloy steel. Int $\mathrm{J}$ Fatigue 24:1003-1010

43. Rumelhart DH, Hinton GE, Williams RJ (1986) Chapter 8. In: Rumelhart DE, McClelland JL (eds) Learning internal representation by error propagation: parallel distributed processing, vol 1 . MIT Press, Cambridge, MA

44. Najjar YM, Basheer IA, McReynolds R (1996) Neural modelling of Kansas soil swelling. Transp Res 1526:14-19

45. Kim H, Rauch AF, Haas CT (2004) Automated quality assessment of stone aggregates based on laser imaging and a neural network. J Comput Civil Eng 18(1):58-64

46. Singh TN, Gupta AR, Sain R (2006) A comparative analysis of cognitive systems for the prediction of drillability of rocks and wear factor. Geotech Geol Eng 24:299-312

47. Erzin Y, Rao BH, Singh DN (2008) Artificial neural networks for predicting soil thermal resistivity. Int J Therm Sci 47:1347-1358

48. Erzin Y, Rao BH, Patel A, Gumaste SD, Gupta AK, Singh DN (2010) Artificial neural network models for predicting of electrical resistivity of soils from their thermal resistivity. Int J Therm Sci 49:118-130

49. Goh ATC (1995) Back-propagation neural networks for modelling complex systems. Artif Intell Eng 9:143-151

50. Goh ATC (1995) Modelling soil correlations using neural networks. J Comput Civil Eng 9:275-278

51. Shahin MA, Jaksa MB, Maier HR (2001) Artificial neural network applications in geotechnical engineering. Aust Geomech 36(1):49-62

52. Shahin MA, Maier HR, Jaksa MB (2004) Data division for developing neural networks applied to geotechnical engineering. J Comput Civil Eng 18(2):105-114

53. Shahin MA, Jaksa MB (2005) Neural network prediction of pullout capacity of marquee ground anchors. Comput Geotech 32:153-163

54. Demuth H, Beale M, Hagan M (2006) Neural network toolbox user's guide. The Math Works Inc., Natick

55. Youd TL, Idriss IM, Andrus RD, Arango I, Castro G, Christian JT, Dobry R, Finn WDL, Harder JLF, Hynes ME, Ishihara K, Koester JP, Liao SSC, Marcuson WF, Martin GR, Mitchell JK, Moriwaki Y, Power MS, Robertson PK, Seed RB, Stoke KH (2001) Liquefaction resistance of soils: summary report from the 1996 NCEER and 1998 NCEER/NSF workshops on evaluation of 
liquefaction resistance of soils. $\mathrm{J}$ Geotech Geoenviron 127(10):817-833

56. Boulanger RW (2003) High overburden stress effects in liquefaction analyses. J Geotech Geoenviron 129(12):1071-1082

57. Bolton MD, Gui MW (1993) The study of relative density and boundary effects for cone penetration tests in centrifuge. Technical Report: CUED/D-SOILS/TR256. Department of Engineering, Cambridge University

58. Jamiolkowski M, Baldi G, Bellotti R, Ghionna V, Pasqualini E (1985) Penetration resistance and liquefaction of sands. In: Proceedings of the 11th international conference on soil mechanics and foundation engineering, San Francisco

59. Cai GJ, Liu SY, Cheng Y, Zou HF, Du GY, Ren BB, Puppala AJ (2013) In situ evaluation of relative density from piezocone penetration tests of clean sand from China. Geotechnical and geophysical site characterization 4 . In: Proceedings of the 4th international conference on site characterization 4, ISC-4, vol 1, pp 207-211

60. Teh CI, Houlsby GT (1991) An analytical study of the cone penetration test in clay. Geotechnique 41(1):17-34

61. Parez L, Fauriel R (1988) Le piezocone ameliorations apportees a la reconnaissance de sols. Rev Francaise de Geotech 44:13-27

62. Darcy H (1856) Les Fontaines Publiques de la Ville de Dijon. Dalmont, Paris

63. Robertson PK (2009) Interpretation of cone penetration tests-a unified approach. Can Geotech J 46(11):1337-1355

64. Robertson PK, Wride CE (1998) Evaluating cyclic liquefaction potential using the cone penetration test. Can Geotech J 35(3):442-459

65. Masters $\mathrm{T}$ (1993) Practical neural network recipes in $\mathrm{C}++$. Academic Press, San Diego
66. Hornik K, Stinchcombe M, White H (1989) Multilayer feedforward networks are universal approximators. Neural Netw 2:359-366

67. Sakellariou MG, Ferentinou MD (2005) A study of slope stability prediction using neural networks. Geotech Geol Eng 23:419-445

68. Banimahd M, Yasrobi S, Woodward PK (2005) Artificial neural network for stress-strain behavior of sandy soils: Knowledge based verification. Comput Geotech 32:377-386

69. Gokceoglu C, Zorlu K (2004) A fuzzy model to predict the uniaxial compressive strength and the modulus of elasticity of a problematic rock. Eng Appl Artif Intell 17:61-72

70. Finol J, Guo YK, Jing XD (2001) A rule based fuzzy model for the prediction of petrophysical rock parameters. J Pet Sci Eng 29:97-113

71. Gokceoglu C (2002) A fuzzy triangular chart to predict the uniaxial compressive strength of Ankara agglomerates from their petrographic composition. Eng Geol 66(1-2):39-51

72. Kanibir A, Ulusay R, Aydan O (2006) Liquefaction-induced ground deformations on a lake shore (Turkey) and empirical equations for their prediction. IAEG2006, Paper 362

73. Cabalar AF, Cevik A (2009) Modeling damping ratio and shear modulus of sand-mica mixtures using neural networks. Eng Geol 104:31-40

74. Cevik A, Sezer EA, Cabalar AF, Gokceoglu C (2011) Modeling of the uniaxial compressive strength of some clay-bearing rocks using neural network. Appl Soft Comput 11(2):2587-2594

75. Köroğlu MA, Köken A, Arslan MH, Çevik A (2013) Neural network prediction of the ultimate capacity of shear stud connectors on composite beams with profiled steel sheeting. Sci Iran 20(4):1101-1113 